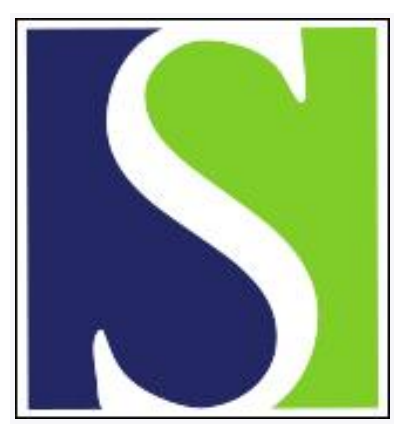

Scand J Work Environ Health 1987;13(4):356-357

https://doi.org/10.5271/sjweh.2028

Issue date: Aug 1987

Tests employed in Japan for the investigation of peripheral circulatory disturbances due to hand-arm vibration exposure. by Matsumoto T

Affiliation: Department of Public Health, Nagoya City University Medical School, Japan.

This article in PubMed: www.ncbi.nlm.nih.gov/pubmed/3433038

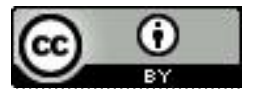




\title{
Tests employed in Japan for the investigation of peripheral circulatory disturbances due to hand-arm vibration exposure
}

\author{
by Tadao Matsumoto, MD ${ }^{1}$

\begin{abstract}
MATSUMOTO T. Tests employed in Japan for the investigation of peripheral circulatory disturbances due to hand-arm vibration exposure. Scand J Work Environ Health 13 (1987) 356-357. Tests for the investigation of peripheral circulatory function are thought, in Japan, to be of primary importance for the proper diagnosis of the hand-arm vibration syndrome. The complaints presented in connection with Raynaud's phenomenon (finger skin blanching, numbness, cold sensation, and pain in the hands) should be thoroughly assessed. In evaluating the results of skin temperature measurements and the nail compression test before and after cold provocation by immersion of the hands in cold water, seasonal and diurnal variation, as well as differences in room temperature, temperature of the cooling water, duration of cooling time, etc, must be taken into account.
\end{abstract}

Key terms: cold provocation, nail compression test, Raynaud's phenomenon, room temperature, thermography, vibration syndrome.

In 1973, the Japanese Ministry of Labour issued rules for the examination of persons with suspected damage caused by hand-held vibrating tools (9). The examination procedures currently used in Japan consist of the assessment of complaints (frequency, distribution on the hand, and seasonal occurrence of Raynaud's phenomenon, numbness, pain, etc, in the upper and lower extremities) and laboratory tests. For clinical purposes the laboratory tests include skin temperature measurements with contact thermometry and/or thermography. In research, or in some cases needing a special examination, blood flow measurement, nail bed capillaroscopy, angiography, assessment of beta-thromboglobulin and hemagglutination capacity, etc, are also used. Vibratory and pain perception thresholds and peripheral nerve conduction velocity - dysfunctions in which are considered in Japan to occur in parallel with signs of peripheral circulatory disturbances - are often assessed.

\section{Factors influencing skin temperature measurements and the nail compression test}

In the evaluation of the results of skin temperature measurements and the nail compression test at rest and after cold provocation, seasonal and diurnal variation and differences in room temperature, in the temperature of the water used for cooling the hands, and in the duration of cooling must be taken into account.

\footnotetext{
1 Department of Public Health, Nagoya City University Medical School, Nagoya, Japan.
}

Reprint requests to: Dr T Matsumoto, Department of Public Health, Nagoya City University Medical School, Kawasumi Mizuho-cho, Mizuho-ku, Nagoya 467, Japan.

\section{Seasonal variation}

The results of cold provocation by hand immersion in cold water have been shown to vary with the time of year. In an investigation by Azuma (2), one hand was immersed to the wrist in water at 5,10 , and $15^{\circ} \mathrm{C}$ for $10 \mathrm{~min}$ at a room temperature of $20^{\circ} \mathrm{C}$. Fingertip skin temperature in the autumn was lower than in spring but similar to that measured in the winter. Finger skin temperature measured in the spring was observed to be similar to the summer values. The same differences were noted for recovery time after cold provocation. The recovery after cold water immersion in summer and spring was faster than in autumn and winter. In work by Harada et al (5) and Hirosawa et al (6), cold provocation consisted of immersing one hand to the wrist in $10^{\circ} \mathrm{C}$ water for $10 \mathrm{~min}$ at room temperatures of 10,20 , and $30^{\circ} \mathrm{C}$ at four different times of the year (August, November, February, and May). The finger skin temperature and nail compression values and the vibration sense thresholds were better evaluated in summer and spring than in autumn and winter.

\section{Diurnal variation}

Finger skin temperature has been found (1) to depend on several factors which vary during the day, such as the interval after meals, duration of sunshine, rhythm of body functions, etc, but the precise circumstances of this variation are still unclear.

\section{Room temperature}

Skin temperature, nail compression test results, and vibration sense thresholds have been shown to be influenced by room temperature (4), most pronouncedly around $20^{\circ} \mathrm{C}$. These findings seem to be supported by the results of Kurumatani and his col- 
laborators (8) that room temperatures between 18 and $22^{\circ} \mathrm{C}$ produce a greater difference between a vibrationexposed group and a reference group than room temperatures of $18-22^{\circ} \mathrm{C}$ and $>22^{\circ} \mathrm{C}$.

\section{Temperature of the cooling water}

It has been claimed (7) to be possible to discriminate subjects with the hand-arm vibration syndrome from healthy persons by cold water immersion of the hand to the wrist in water at 10 and $5^{\circ} \mathrm{C}$. The results of Cheng-Po (3) suggest that measuring the rate of recovery at 5 and $10 \mathrm{~min}$ after cold provocation with a water temperature of $10^{\circ} \mathrm{C}$ is optimal for the evaluation. In the last-mentioned work, self-rating scores revealed that the complaints of pain at immersion were milder with $10^{\circ}$ than with $5^{\circ} \mathrm{C}$ water. Currently, cold provocation is most frequently performed with a water temperature of $5^{\circ} \mathrm{C}$.

\section{Duration of cooling time}

The question of the adequate duration for the cold provocation has not been fully clarified in Japan, but cold water immersion for $10 \mathrm{~min}$ in $5^{\circ}$ or $10^{\circ} \mathrm{C}$ water is commonly considered appropriate (7).

\section{Optimization of the clinical examinations}

A question often discussed in Japan concerns the optimal conditions under which laboratory examinations with regard to circulatory disturbances should be performed. Among the factors involved are, for instance, whether the procedure is too complicated or troublesome for the patient and whether the examination takes too long. The commonly noted discrepancy between complaints and objective findings has also been discussed.

A large variation in the examination methods currently used appears to exist in Japan. According to the replies to a questionnaire (4) conducted in 1977, most clinics perform skin temperature measurements and the nail compression test; some also use plethysmography. In some clinics, additional examinations are made, including thermography, capillaroscopy, and angiography. The physical examination is primarily carried out at room temperatures of 20 to $23^{\circ} \mathrm{C}$. Blood circu- latory disturbances are generally assessed by cold provocation in $5^{\circ}$ or $10^{\circ} \mathrm{C}$ water for $10 \mathrm{~min}$. It was pointed out that a clear description of the conditions under which the tests were made should accompany all medical certificates concerning the assessment of peripheral circulatory disturbances.

Finally, it should be mentioned that a worker using hand-held vibrating tools must have a special examination made at regular intervals. The aim of the examination should be the assessment of various pathological symptoms and signs. This procedure is considered to be an important regulation for the early detection of the hand-arm vibration syndrome.

\section{References}

1. Asano H, Fujiki Y, Kohno Y. On the variation of the temperature of the skin of hands and fingers during a day. [in Japanese]. In: Proceedings of the 57th annual meeting of the Japanese Association of Industrial Health [in Japanese]. Japanese Association of Industrial Health, Tokyo 1984, pp 676-677.

2. Azuma T. A study on the seasonal variation of the effects of hand immersion in cold water on finger tip skin temperature and pain [in Japanese]. Jpn J Ind Health 22 (1980) 24-39. (English summary).

3. Cheng-Po C. Cold water immersion test in patients with vibration disease [in Japanese]. Jpn J Ind Health 18 (1976) 453-463. (English summary).

4. Committee on Vibration Hazards, Japanese Association of Industrial Health. Report on committee work. Tokyo 1980.

5. Harada N, Hirosawa I, Fujii M, Dodo H. Seasonal variation of circulatory and sensory functions during immersion test in cold water for vibration syndrome [in Japanese]. Jpn J Ind Health 25 (1983) 422-431. (English summary).

6. Hirosawa I, Harada N, Dodo H, Fujii M. Cold immersion test for vibration disease under various room temperatures [in Japanese]. In: Proceedings of the 54th annual meeting of the Japanese Association of Industrial Health [in Japanese]. Japanese Association of Industrial Health, Tokyo 1981, pp 442-443.

7. Iwata H. Vibration syndrome [in Japanese]. Kindai Press, Tokyo 1978, pp 80-81.

8. Kurumatani N, Iki M, Hirata K, Moriyama T, Satoh M, Arai T. Study of room temperatures at cooling load test $\left(10^{\circ} \mathrm{C}, 10 \mathrm{~min}\right)$ as a means of mass examination of workers using vibrating tools [in Japanese]. In: Proceedings of the 59th annual meeting of the Japanese Association of Industrial Health [in Japanese]. Japanese Association of Industrial Health, Tokyo 1986, pp 158-159.

9. Ministry of Labour, Japan. Notification no 597 [in Japanese]. Tokyo 1973. 